\title{
Design and Testing of an Improved Spring-Type Cone in Liner Hangers
}

\author{
Ming Zhao \\ Schlumberger Technology Corp., \\ 7030 Ardmore Street \\ Houston TX, 77054 USA
}

\author{
Asif Javed \\ Schlumberger Technology Corp., \\ 7030 Ardmore Street \\ Houston TX, 77054 USA
}

\begin{abstract}
A spring-type cone is designed to replace the conventional lower cone in liner hanger systems to keep the hanger slips and elastomer elements always energized even after the load reversals. Based on the load-deflection requirement in the worstcase scenario, the concept of a slotted cylinder spring was proposed to rework the current lower cone. The mathematical model using linear elasticity was firstly developed to bring the concept to a preliminary design. Nonlinear numerical models with the finite element method were then employed to simulate the real loading/unloading conditions. With the results analyzed the final design was optimized. The experimental data obtained from a prototype lab testing was compared with the numerical results to validate the model and confirm the spring's performance.
\end{abstract}

Keywords - Cone; Deflection-residual load; Finite element analysis; Liner hanger system; Slotted cylinder spring

\section{INTRODUCTION}

A liner hanger system usually consists of a hanger to provide anchoring and a liner top packer to provide sealing. The hanger is a mechanical device that anchors the liner to the previously installed well casing. The major benefit of using liners is cost savings due to less use of casing and cement [1]. In conventional liner hanger systems, the liner hanger carries load in one direction, i.e. in the downward direction. Hold down slips on the liner top packer carries the load in the opposite direction, preventing any upward movement usually due to well discharge or pumping treatment. As the wells are getting deeper and because of the usage of the liners with bigger diameter and lighter weight, the worst-case discharge load could be equal to or greater than the total hanging load from the liners [2-5]. The same case would happen in the wells with hydraulic fracturing operations $[6,7]$. Since the hanger slips and packer element are not spring loaded, in case of high reversal load the conventional liner hangers are prone to failure. The Bureau of Ocean Energy Management, Regulation, and Enforcement (BOEMRE) requires wells to be designed for worst-case discharge criteria [8], which affects the design and testing of liner hanger systems as well. In this paper, a spring-type lower cone is proposed as a quick solution to mitigate the risk of discharge due to reversal load.

In the example liner hanger system, which has the liner hanger and liner top packer combined into one system, a lower cone is located between the slips and the packer element as shown in Fig. 1. The lower cone is pinned to the slips by shear screws to transfer the setting load to the element during initial setting. After the shear value is reached, the cone profile in contact with the slips will lift the slips up to engage the casing ID. A ratchet lock ring is placed under the cone to prevent the element springing back after the setting load is removed.
To simulate the upward load on the system, a reversal load test will be performed after the hanger/packer is set. In the example liner hanger system, a reversal load test is performed by putting a maximum of $667.2 \mathrm{kN}(15000 \mathrm{lbf})$ load on the mandrel body with the slips and packer element in set condition. This large force will further compress the body mandrel, move forward the lock ring over more ratchets, and push the slip wickers to bite more deeply into the casing. After removing the reversal load, a significant back-off in axial displacement will be expected due to the mandrel stretch, ratchet disengagement, and slip wicker retraction. The calculation shows that, in a worstcase scenario, a maximum of $1.01 \mathrm{~cm}$ axial back-off will be seen in the example system. Considering the total stroke during setting, the $1.01 \mathrm{~cm}$ back-off could potentially cause the slip or the element to retract from optimal set condition (without reversal load applied and removed). To resolve this issue, a spring-type cone is needed to keep the slips/element energized during the reversal load.

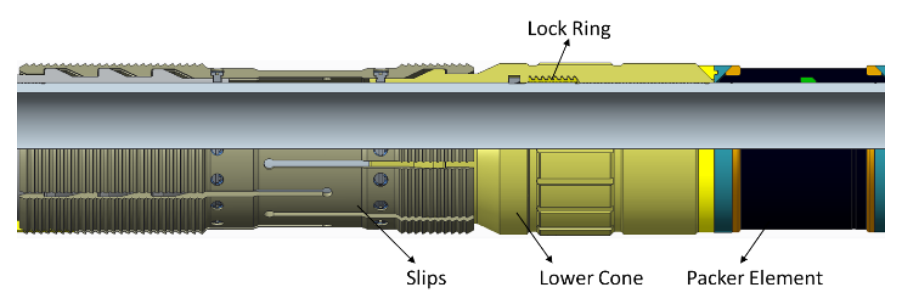

Fig. 1. Slips, Lower Cone and Packer Element in the Example Liner Hanger System

The minimum required setting load could be up to $133.4 \mathrm{kN}$ for optimal element expansion, which is a relatively high load for a spring with limited length $(38.1 \mathrm{~cm}$ in effective length of the current design). A slotted cylinder spring [9-11] was proposed to as the solution. Cutting the slot patterns on the lower cone body requires minimum rework of the existing part and therefore is cost-effective. To bring this concept to a functional design, a mathematical model was first developed to help create the preliminary design. Numerical simulation with the finite element method was then used to evaluate and optimize the design. Lastly the prototypes of the spring cone were tested in the lab to validate the model and confirm the simulation.

\section{ANALYTICAL MODEL}

A typical slotted cylinder spring is shown in Fig. 2. The design parameters and symbols are also defined on the drawing. The spring can be considered as a series of coupled cantilever beams arranged in parallel. Therefore, the load-deflection relationship of the whole spring can be calculated based on the classic cantilever deflection theory as reported by Schneider $[11]$. 
Each slot works as an individual cantilever with a size of Length $\times$ Height $\times$ Width $=\mathrm{L} \times \mathrm{h} \times \mathrm{b}$ (see Fig. 2). Because the adjacent slot section has a 90-degree rotated pattern, the load is applied in the middle of the beam. Assuming load $\mathrm{P}$ is applied, the deflection of each slot is

$$
\delta_{S}=\frac{L^{3} P}{16 b h^{3} E}
$$

where E is the Young's modulus of the material. To develop a general formula, it is assumed here that each slot section consists of parallel arrangement of slots with a number of $\mathrm{N}_{\mathrm{S}}$. The deflection of one section is

$$
\delta_{S S}=\frac{\delta_{S}}{N_{S}}
$$

The total deflection of NSS serially arranged slot sections (ss) is

$$
\delta_{\text {tot }}=\frac{N_{S S}}{N_{S}} \delta_{S}
$$

Combining Eqs. (1) and (3) yields the total deflection as a function of the load applied:

$$
\delta_{\text {tot }}=\frac{N_{S S}}{N_{S}} \cdot \frac{L^{3} P}{16 b h^{3} E}
$$

Rewriting Eq. (4) gives the stiffness of the spring:

$$
K=\frac{P}{\delta_{\text {tot }}}=\frac{16 N_{S} b h^{3} E}{N_{S S} L^{3}}
$$

It should be noted that the end "beams" of the spring are considered ineffective units because they are not relied upon to add to the spring effect but merely to transfer the load to the rest of the spring. Therefore, the parameter NSS should be defined as the effective number of slot sections in the above discussion and the total length of the spring is

$$
L_{S}=\left(N_{S S}+1\right) \cdot(h+W O C)+h(6)
$$

Like any other spring, the design of a slotted cylinder spring depends on its material properties, geometric parameters and the load-deflection relation. The material selected is the $1034.2 \mathrm{MPa}$ steel (Young's modulus, $\mathrm{E}=206.8 \mathrm{GPa}$ ). Eqs. (4)-(6) provide the fundamental relation between the spring's load-deflection performance and its geometric parameters. Table 1 lists all the design values for the spring geometric parameters. With the OD and ID same as the previous conventional lower cone in the example system, wall thickness and slot length can be calculated. The number of slots per section is chosen to be 2 to facilitate the rework process. For the same concern, the width of cut was set at $0.635 \mathrm{~cm}(0.25$-in. $)$, based on the available mill size.
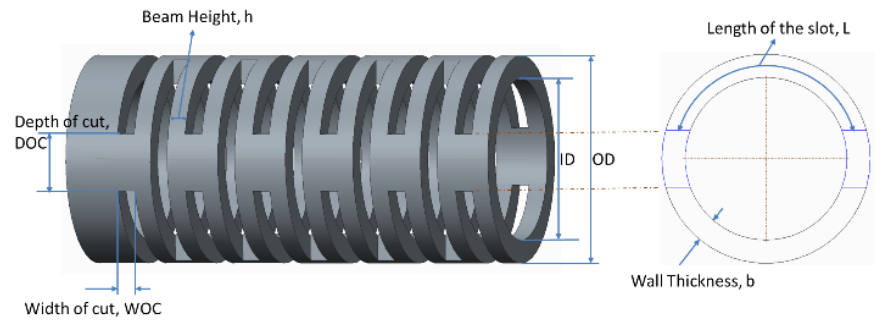

Fig. 2. A Typical Slotted Cylinder Spring
Table 1. Geometric Parameters of the Spring Cone

\begin{tabular}{|c|c|}
\hline Geometric Parameter & Design Value \\
\hline Outside diameter (OD), cm & 14.851 \\
\hline Inside diameter (ID), cm & 11.534 \\
\hline Wall thickness (b), cm & 1.659 \\
\hline Length of the slot (L), cm & 20.724 \\
\hline Width of Cut (WOC), cm & 0.635 \\
\hline Number of slots per section $\left(\mathrm{N}_{\mathrm{S}}\right)$ & 2 \\
\hline Number of sections, $\left(\mathrm{N}_{\mathrm{sS}}\right)$ & TBD \\
\hline Beam height $(\mathrm{h}), \mathrm{cm}$ & TBD \\
\hline Depth of Cut (DOC), cm & TBD \\
\hline
\end{tabular}

\section{DESIGN BOUNDARIES}

The analytical model derived in the last section shows how the spring performance is governed by its geometric parameters. However, this model is only valid within the linear elastic range. In the example liner hanger system, the spring cone must remain solid at the setting load to avoid further compression when the reversal load is applied. The solid height is defined as the length of the spring when it is compressed until each beam bears solidly against those adjoining it. In such a case, the deflection per slot is equal to the width of cut. Here, the parameter $\alpha$ is defined as the ratio of elastic deflection over the total deflection in each slot:

$$
\delta_{S}=\alpha \cdot W O C
$$

From previous study [11], $\alpha$ must be less than 0.8 for structural stability. However, imprecision in material properties and plastic yield will make the spring stiffness deviate from its ideal calculated value. To compensate that, a ratio of $\alpha=0.6$ was used to design for safety. Previous study [11] also found that the depth of the cut must fall into an optimal range:

$$
\text { DOC }=\frac{(\mathrm{h}+\mathrm{WOC})}{1.6} \cdot(1 \pm 5 \%)
$$

Equations (7) and (8) are the design limitations from previous research findings, from which a preliminary design can be created.

To better ensure the slotted spring design would be flexible enough to accommodate different load requirements on the slips and packer element, the design had to consider moving the lock ring to the middle of the spring cone. By doing so, the spring cone works as one spring during loading, whereas upon unloading, with the lock ring engaged, it works as two individual springs. This is illustrated in Fig. 3. For the example liner hanger system, the corresponding back-off deflection for each spring is calculated to be $0.663 \mathrm{~cm}$ for the slips side and $0.343 \mathrm{~cm}$ for the element side. The minimum load required to set the slips and element are $8.9 \mathrm{kN}$ and $133.4 \mathrm{kN}$, respectively. During the setting process, $266.9 \mathrm{kN}$ will be applied on the slips and then transmitted to the element through the spring cone. As explained, the spring needs to be fully compressed at $266.9 \mathrm{kN}$. These values could vary for other liner hanger systems. They are used here to explain the design methodology. Turning these requirements into equations: 


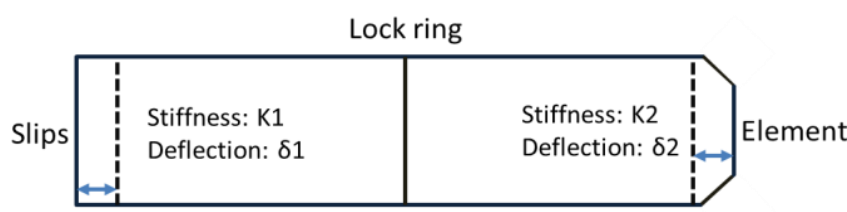

Fig. 3. Schematic Diagram of the Spring Cone

$$
\begin{gathered}
\delta_{1}=\frac{266.9}{K_{1}} \quad \delta_{2}=\frac{266.9}{K_{2}} \\
\delta_{1}-0.663 \leq \frac{8.9}{K_{1}}(10) \\
\delta_{2}-0.343 \leq \frac{133.4}{K_{2}}
\end{gathered}
$$

Combining Eqs. (9)-(11), it's possible to calculate that $\delta_{1}, \delta_{2}$ $\geq 0.69$. With Eqs. (3) and (7), this means:

$$
\delta_{\text {tot }}=\frac{N_{S S}}{N_{S}} \cdot \alpha \cdot W O C \geq 0.69
$$

which means that $\mathrm{N}_{\mathrm{SS}} \geq 3.6$, meaning that the minimum number of effective sections is 4 (total number of sections $=5$ ). Substituting $\mathrm{N}_{\mathrm{SS}}=4$ into Eq. (5) enabled calculation of the beam height, $\mathrm{h} \leq 2.324 \mathrm{~cm}$. And according to Eq. 8, DOC must be less than $1.753 \mathrm{~cm}$.

\section{FINITE ELEMENT SIMULATION}

\section{A. Model Setup}

Taking consideration of the design limitations discussed above, the first preliminary spring cone is designed to have NSS $=4, \mathrm{~h}=2.311 \mathrm{~cm}$ and DOC $=1.524 \mathrm{~cm}$. The model was created in CAD package and then exported to Abaqus finite element software [12]. To minimize the model size, only one-quarter of the spring cone is simulated with symmetric boundary conditions, as shown in Fig. 5(a).

The spring cone is modelled using an isotropic elasto-plastic steel (density = 7.861 g/cm3; Young's modulus, $\mathrm{E}=206.8 \mathrm{GPa}$; Poisson's ratio $=0.29$; yield strength $=1034.2 \mathrm{MPa}$ ). The true stress vs. true strain curve was estimated from a test data of the 1034.2 MPa steel as shown in Fig. 4. The part is then meshed into 23,843 quadratic tetrahedral elements. Because the slots may close during spring compression, general contact with "hard" normal behavior and 0.13 frictional tangential behavior (from in-house friction test data) was defined in Abaqus for selfcontact.

During the simulation, the setting load is applied uniaxially to compress the spring to solid. Then the reversal load is applied to further compress the spring. As only one-quarter of the cone is modelled, the setting or reversal load applied is divided by four. The next step is to simulate the lock ring engagement by fixing the lock ring profile at the current position and then relaxing both ends to obtain the spring load upon backing off. Nonlinear effects of plasticity and contacts were included in the simulation.

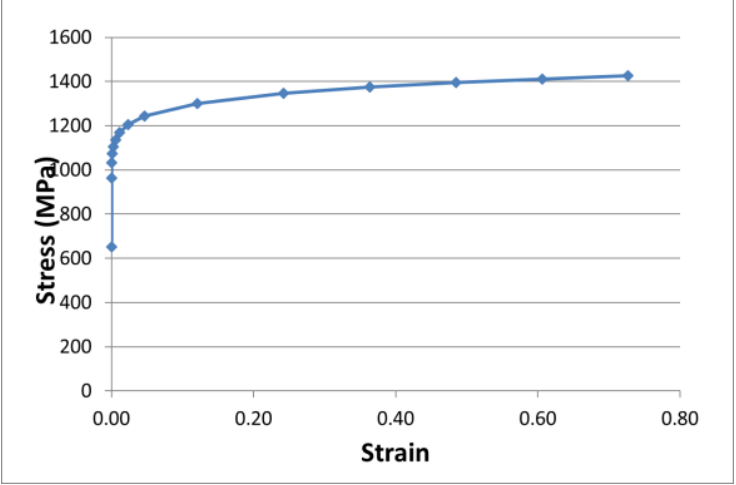

Fig. 4. Elastoplastic Materials Model
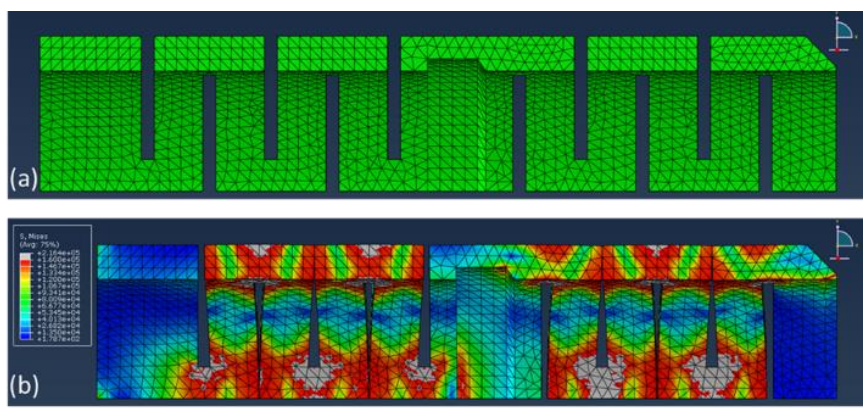

Fig. 5. Mesh of 1/4 Spring Cone Model (a) and Von Mises Stress at 266.9 kN Setting Load (b), Preliminary Design

\section{B. FEA-Based Optimization}

Deformation and von Mises stress contour at the setting load of $266.9 \mathrm{kN}$ is shown in Fig. 5(b). Fig. 6 shows the spring cone's load-deflection response during loading of the whole spring and unloading as two springs with the lock ring engaged. According to Fig. 5 (b), the remaining loads at $0.343 \mathrm{~cm}$ and $0.663 \mathrm{~cm}$ backoff are calculated to be $125.9 \mathrm{kN}$ and $12.0 \mathrm{kN}$, respectively. This is in close agreement with the design objective of $133.4 \mathrm{kN}$ and $8.9 \mathrm{kN}$. The elastic (reversible) deflection on each side of the spring is about $0.699 \mathrm{~cm}$, according to the unloading plot. The parameter $\alpha$ can be back calculated: $\alpha=0.699 \times 2 / 2.456=0.57$ $(2.456 \mathrm{~cm}$ is the total deflection at $266.9 \mathrm{kN})$, which is approximately equal to the assumption of 0.6.

However, several issues were also identified from the FEA results. First, the spring cone did not go completely solid at $266.9 \mathrm{kN}$. The deformation plot in Fig. 5 shows that four end slots did not close, although the rest were fully in contact. The reason, as discussed, is that the end beams of the spring are "ineffective" in contributing to the spring response. Thus, the end slots are only closed by half due to the deflection of the adjoining beams. Secondly, by zooming into the closed slots (Fig. 7), it is found that the OD of the slots makes contact before the ID. This non-uniformity is caused by the different arc length of the OD and ID edges due to the 3D structure of the spring cone. 


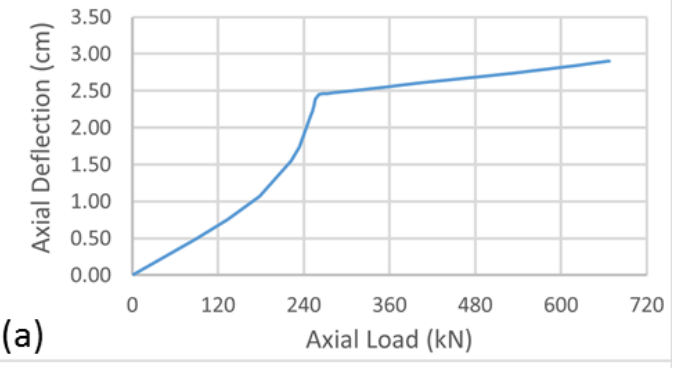

(a)

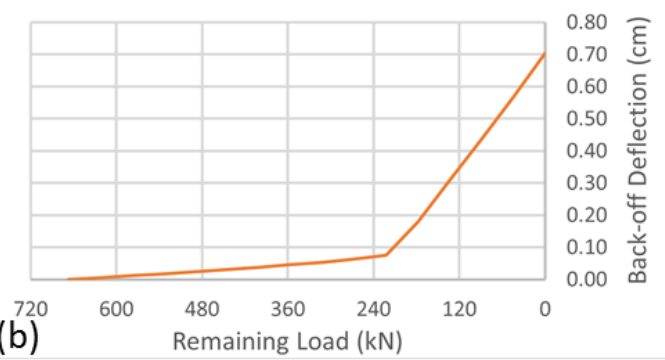

Fig. 6. Deflection vs. Load of the Spring Cone during Loading (a) and Unloading (b), Preliminary Design

Because of the remaining gaps at the end slots and the ID edges, the spring cone will be still compressible with larger loads applied. This is confirmed on the loading plot in Fig. 6, showing that the spring cone was further compressed by $\sim 0.508 \mathrm{~cm}$ from $266.9 \mathrm{kN}$ to $667.2 \mathrm{kN}$.

To resolve the issues identified in the FEA results, the following optimizations were implemented to improve the current design as illustrated in Fig. 8:

1. Two symmetric nubs were added to each end slot to reduce the gap by half. This forces the end slots to close so that the spring deforms to fully solid at setting load;

2. The straight-cut slots were changed to radially cut slots, which reduces the length differences between the OD and ID edges and allows the beam to bend more uniformly;

3. Full radius rounds were added to the slot ends to reduce stress concentrations.

The new model was simulated using the same setup in Abaqus. The results show obvious improvement that the additional compression from $266.9 \mathrm{kN}$ to $667.2 \mathrm{kN}$ was reduced to $0.069 \mathrm{~cm}$.
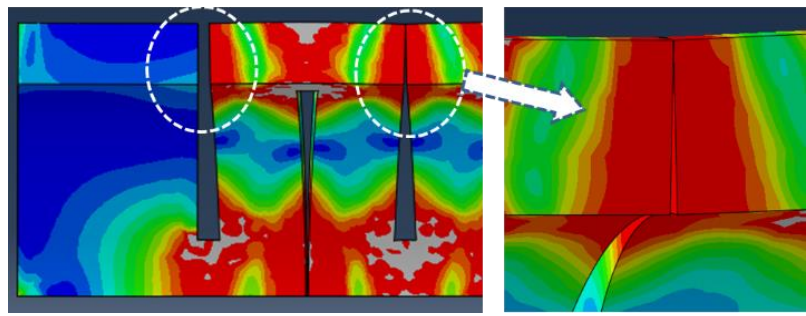

Fig. 7. Zoom View of the Slot Closure at Setting Load

\section{Final Design and Simulation}

During the design and optimization of the spring cone, the example slips were also tested and improved. As a result, the load requirement was reduced to $4.4 \mathrm{kN}$ to keep the slips in set position. Because the thread pitch size of the ratchet is $0.160 \mathrm{~cm}$, in case of accidental ratchet movements, the back-off deflection needs to be able to compensate at least two ratchets of engagement (back-off deflection $=0.663+0.160 \times 2=0.983$ $\mathrm{cm})$. In such a case, after several optimization iterations, the spring cone was designed to include one more slot on the element side and two more slots on the slips side. To compensate the effect on the spring's stiffness, the angle of cut (AOC) was carefully adjusted to 140 degrees and 160 degrees for the element side and slip side, respectively. By doing so, the spring cone is made with additional flexibility to suit the lower load but with more stroke. The beam height was calculated according Eq. 6 without affecting the total length of the spring cone.

Fig. 9 shows the final design of the spring cone optimized by FEA. Additional features were added to the spring, which are outside the scope of this paper. The deformation and stress distribution with the setting load applied are shown in Fig. 10. The nubs at the end slots and the radial cuts work effectively to close all the gaps, which turns the spring into a solid piece. Fullradius rounds help reduce the stress concentration. The loaddeflection curves were plotted in Fig. 11-13. From unloading, the remaining load was obtained to be $120.1 \mathrm{kN}$ at $0.343 \mathrm{~cm}$ back-off for the element side and $16.9 \mathrm{kN}$ at $0.983 \mathrm{~cm}$ back-off for the slip side. These results were reviewed and agreed to meet the design requirement for the example liner hanger system. As the spring cone is a key component to the example liner hanger system, prototypes of the final model will be manufactured and tested in the lab, which is discussed in the next section.

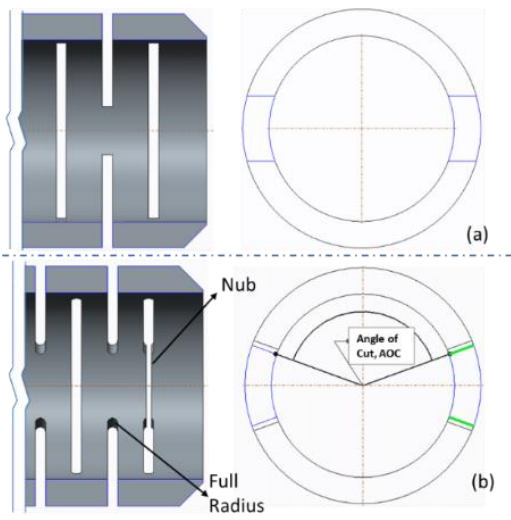

Fig. 8. Design Optimization- Preliminary Design (a) vs. Optimized Design (b)

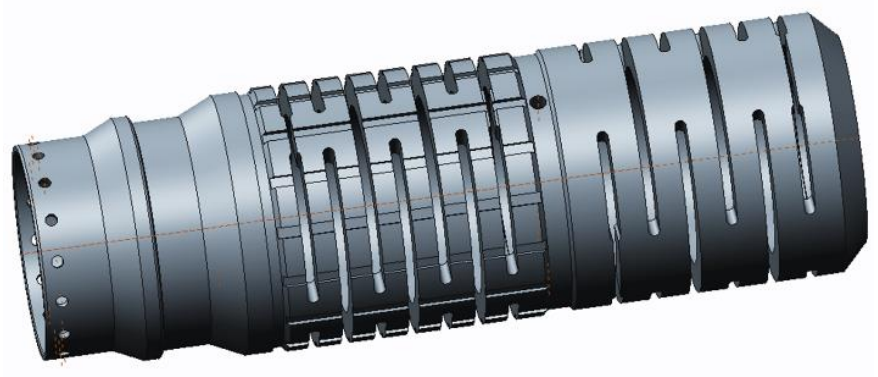

Fig. 9. Optimized Design of the Spring Lower Cone with Full Features Added

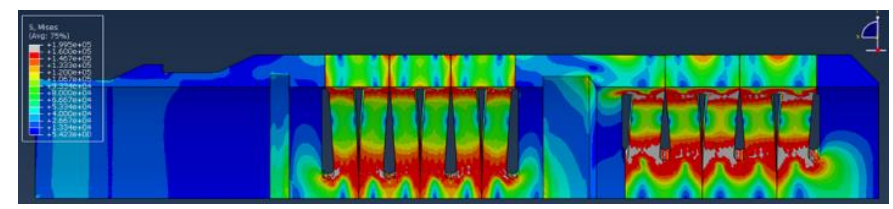

Fig. 10. Deformation and von Mises Stress of the Optimized Design at 266.9 kN Setting Load 


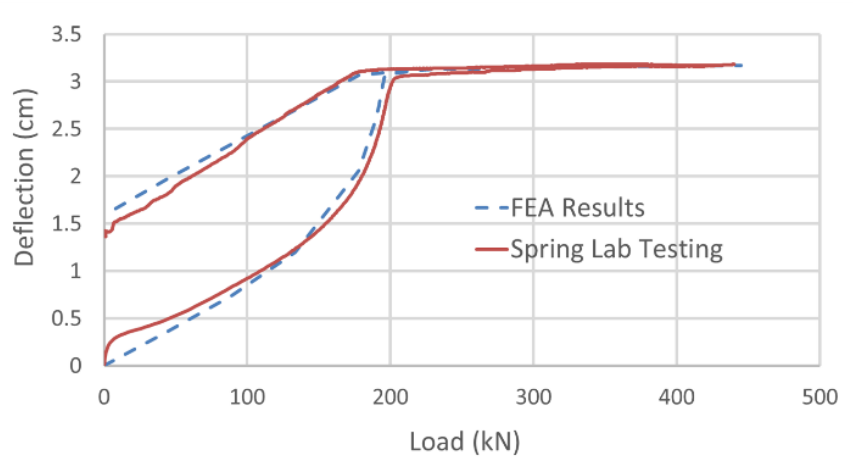

Fig. 11. Comparison of the Load Deflection Curves from FEA Results and Lab Testing

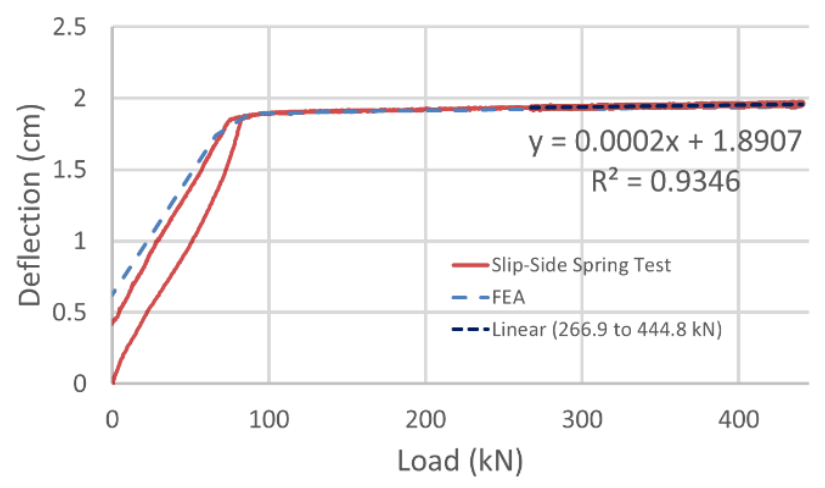

Fig. 12. Load Deflection Curves of the Slip-side Spring

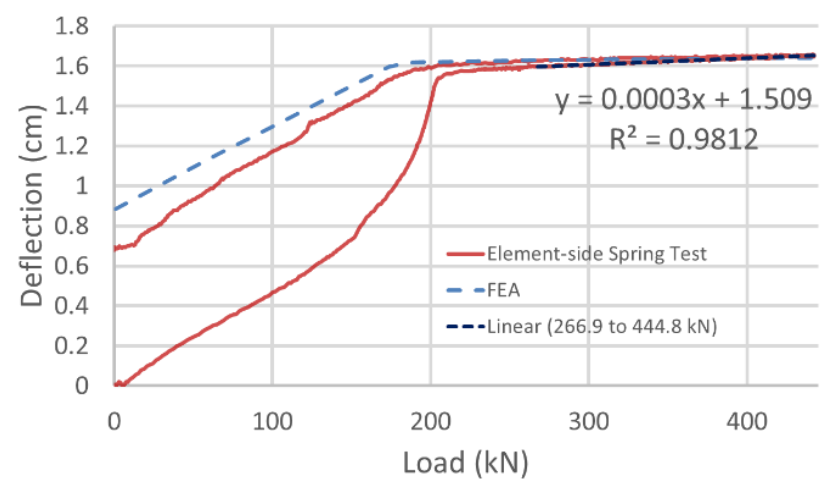

Fig. 13. Load Deflection Curves of the Element-side Spring

\section{EXPERIMENTAL VALIDATION}

The spring cone prototype was manufactured per the final design based on the finite element analysis (Fig. 9). The prototype was then inspected and tested in the lab. As shown in Fig. 14, the spring cone was tested in a press machine with bottom end fixed and compressive load applied to the top end. Transducers installed on the top end was used to measure the displacement. To check the individual performance of the slip-side and element-side spring, a second spring cone was cut and tested separately. The load and deflection were recorded and plotted in Fig. 11-13 with the FEA simulation results. Due to the load limit of the press machine, all the tests were carried out to $444.8 \mathrm{kN}$.

From the plots in Fig. 11-13, it is reasonable to conclude that the test data compares well with the FEA prediction. The root mean square deviation (RMSD) is calculated for each compared pairs to assess the errors. RMSD is defined as:

$$
R M S D=\sqrt{\frac{\sum_{i=1}^{n} e_{i}^{2}}{n}}
$$

where $e_{\mathrm{i}}$ is the deviation of the FEA prediction from the test data. The RMSD was calculated to be only $2.3 \%$ for the slip-side spring (Fig. 12) and $8.1 \%$ the element-side spring (Fig. 13). The possible causes of the deviations are inaccurate material properties, test machine calibration, and measurement errors.

Since the test can only be carried out up to $444.8 \mathrm{kN}$, the data from 266.9 to $444.8 \mathrm{kN}$ was fitted using a linear equation (shown in Fig. 12 and 13), which can be extrapolated to find the total stroke of the spring for a reversal load of $667.2 \mathrm{kN}$. The deflection from 266.9 to $667.2 \mathrm{kN}$ was found to be $0.109 \mathrm{~cm}$, which is less than the thread pitch size $(0.160 \mathrm{~cm})$ of the ratchet. This ensures that when the reversal load is applied, the compression will not move the spring cone further from the slips. The remaining load obtained from test data shows that in worst-case scenarios, the spring cone can provide $120.1 \mathrm{kN}$ on the element and $13.3 \mathrm{kN}$ on the slips as desired.

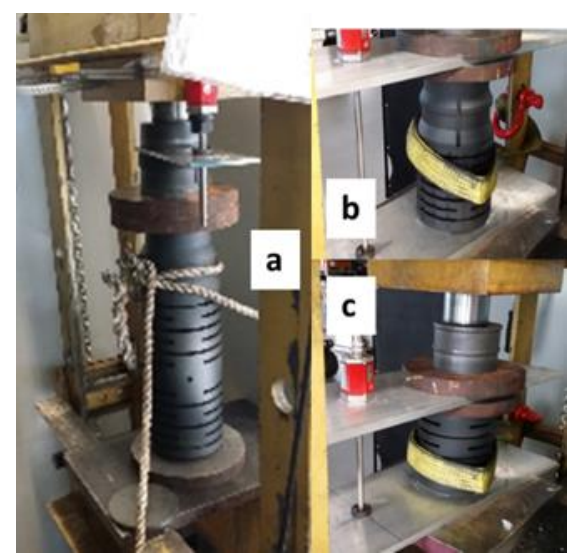

Fig. 14. Spring Cone Tested in a Press Machine. (a) Full Spring Test; (b) Slipside Spring Test; (c) Element-side Spring Test

\section{CONCLUSIONS}

In this paper, a quick and cost-efficient solution was provided to redesign a conventional lower cone to meet the requirement of an additional reversal load test in the example liner hanger system. An analytical model was first derived to understand the governing relations between the geometry and its mechanical properties. A nonlinear finite element approach was used to analyze the preliminary design under the real loading/unloading conditions and identify design problems, which aided in achieving the optimized final design. Prototyping and lab experimental tests were carried out. The data analysis of the test results validated the simulation and confirmed the equipment performance.

The spring-type cone stores energy during the mechanical or hydraulic setting process, which keeps the hanger slips/ packer element energized even with load reversal. This design ensures the improved performance of liner hanger system in case of well discharge or well treatment pumping. The analytical model and finite element approach provide a scheme of understanding similar problems for future equipment design and testing. 


\section{ACKNOWLEDGMENT}

The authors would like to thank the management of Schlumberger Technology Corporation for their support and permission to publish this paper.

\section{Nomenclature:}

$\delta_{s} \quad:$ deflection of each slot, $\mathrm{cm}$

$\delta_{g S} \quad:$ deflection of each section, $\mathrm{cm}$

$\delta_{\text {tot }} \quad:$ total deflection

$N_{g} \quad$ : number of slots per section

$N_{g g} \quad$ : number of section

$P \quad$ : load, $\mathrm{kN}$

K : stiffness, $\mathrm{kN} / \mathrm{cm}$

b : wall thickness, $\mathrm{cm}$

h : beam height, $\mathrm{cm}$

$L \quad$ : length of the slot, $\mathrm{cm}$

DOC : depth of cut

$W O C$ : width of cut

$A O C \quad$ : angle of cut

$O D \quad$ : outer diameter

ID : inner diameter

E : Young's Modulus, GPa

$L_{g} \quad$ : Length of spring, $\mathrm{cm}$

\section{REFERENCES}

[1] A.O. Mohamed, Liner Hangers Technology Advancement and Challenges, In SPE Middle East Oil and Gas Show and Conference, Manama, Bahrain, 1013 March 2013.

[2] E. Eriksen, D. Herrera, M. Moffitt, G.R. Jordan, and G. Mazzaferro, Liner Drilling with a Multi-Set Liner Hanger. In SPE/IADC Middle East Drilling Technology Conference and Exhibition, Society of Petroleum Engineers, January 2011.

[3] R. Gusevik and R. Merritt, Reaching Deep Reservoir Targets Using Solid Expandable Tubulars, In SPE Annual Technical Conference and Exhibition, Society of Petroleum Engineers 2002.

[4] F. Yin, B.K. Gao, D. Huang, and L. Jin, Analysis of Strength and Suspended Load of Liner Hanger in Deep Well. Oil Field Equipment, 9 (2011), p10.

[5] F. Han, L. Gu, X. Cui, F. Li, C.L. Ruan, and B. Feng, Mechanical Model for Setting the Liner Hanger with Embedded Slips, Petroleum Drilling Techniques, 43(06) (2015) 103-107.

[6] S.Q. Zhao, Y.D. He, Y.J. Wei, and X.X. Chen, Research and Application of Special Hanger for Annulus Fracturing, Oil Field Equipment, 4 (2009), p21.

[7] G.E. King and R.L. Valencia, Well Integrity for Fracturing and ReFracturing: What Is Needed and Why? In SPE Hydraulic Fracturing Technology Conference, Society of Petroleum Engineers, 2016

[8] B. Steven, Altering an Existing Well Design to Meet New BOEMRE WorstCase Discharge Criteria, In SPE Drilling \& Completion. Society of Petroleum Engineers, April 2012.

[9] A.I. Razooqi, H.A. Ameen, and K.M. Mashloosh, Static and Dynamic Characteristics of Slotted Cylinder Spring, International Journal of Engineering Research \& Technology, 2 (12) (2013) 3860-3871.

[10]A.I. Razooqi, H.A. Ameen, and K.M. Mashloosh, Compression and impact characterization of helical and slotted cylinder springs, International Journal of Engineering Research \& Technology 3 (2) (2014) 268-278.

[11]W.A. Schneider, Design and application of slotted cylinder springs, USAELRDL Technical Report 2327, 1963

[12]Simulia Abaqus 6.14-1 documentation. 